\title{
A novel thermostable $\beta$-galactosidase from Bacillus coagulans with excellent hydrolysis ability for lactose in whey
}

\author{
Peng Liu, ${ }^{1,2}$ Jiaxiao Xie, ${ }^{1,2}$ Junhua Liu, ${ }^{3}$ and Jia Ouyang ${ }^{1,3,4 *}$ \\ ${ }^{1}$ Jiangsu Co-Innovation Center of Efficient Processing and Utilization of Forest Resources, Nanjing Forestry University, Nanjing 210037, \\ People's Republic of China \\ ${ }^{2}$ College of Forestry, Nanjing Forestry University, Nanjing 210037, People's Republic of China \\ ${ }^{3}$ College of Chemical Engineering, Nanjing Forestry University, Nanjing 210037, People's Republic of China \\ ${ }^{4}$ Jiangsu Province Key Laboratory of Green Biomass-based Fuels and Chemicals, Nanjing 210037, People's Republic of China
}

\begin{abstract}
$\beta$-Galactosidase is one of the most important enzymes used in dairy industry. Here, a novel thermostable $\beta$-galactosidase was cloned and overexpressed from Bacillus coagulans NL01 in Escherichia coli. The phylogenetic trees were constructed using neighborjoining methods. Phylogeny and amino acid analysis indicated that this enzyme belonged to family 42 of glycoside hydrolases. The optimal $\mathrm{pH}$ and temperature were, respectively, 6.0 and 55 to $60^{\circ} \mathrm{C}$. The purified enzyme had a 3.5 -h half-life at $60^{\circ} \mathrm{C}$. Enzyme activity was enhanced by $\mathrm{Mn}^{2+}$. Compared with other $\beta$-galactosidases from glycoside hydrolase family 42 , $B$. coagulans $\beta$-galactosidase exhibited excellent hydrolysis activity. The Michaelis constant $\left(\mathrm{K}_{\mathrm{m}}\right)$ and maximum rate of enzymatic reaction $\left(\mathrm{V}_{\max }\right)$ values for $p$-nitrophenyl- $\beta$-D-galactopyranoside and $o$-nitrophenyl$\beta$-D-galactopyranoside were $1.06 \mathrm{~m} M, 19,383.60 \mathrm{U} / \mathrm{mg}$, and $2.73 \mathrm{mM}, 5,978.00 \mathrm{U} / \mathrm{mg}$, respectively. More importantly, the enzyme showed lactose hydrolysis ability superior to that of the commercial enzyme. The specific enzyme activity for lactose was $27.18 \mathrm{U} / \mathrm{mg}$. A total of $104.02 \mathrm{~g} / \mathrm{L}$ lactose in whey was completely hydrolyzed in $3 \mathrm{~h}$ with addition of $2.38 \mathrm{mg}$ of pure enzyme per gram of lactose. In view of the high price of commercial $\beta$-galactosidase, B. coagulans $\beta$-galactosidase could be a promising prototype for development of commercial enzymes aimed at lactose treatment in the dairy industry. Key words: $\beta$-galactosidase, Bacillus coagulans NL01, lactose hydrolysis, whey
\end{abstract}

\section{INTRODUCTION}

$\beta$-Galactosidase (EC 3.2.1.23), also known as lactase, catalyzes the hydrolysis of $\beta-(1-3), \beta-(1-4)$ or $\beta-(1-6)$

Received June 20, 2019.

Accepted July 8, 2019.

*Corresponding author: hgouyj@njfu.edu.cn galactosyl bonds in oligo- and disaccharides, as well as the reverse reaction, transglycosylation (Nath et al., 2013). The natural substrate for most $\beta$-galactosidases is lactose; hence they are widely used in food processing, especially in the dairy industry, for the production of lactose-free dairy products such as milk drinks, cream, yogurt, and cheese (Nath et al., 2014). Removal of lactose from milk diminishes the lactose intolerance problem that prevails in more than $70 \%$ of the world's adult population. Moreover, due to transglycosylation activity, $\beta$-galactosidase can transfer galactosyl moiety to various compounds. It can therefore be used for the production of galactosylated products, such as galactosyl sucralose (Lu et al., 2012), galactosyl fucose (Oh et al., 2019), alkyl galactopyranoside (Yang et al., 2017), and galactosyl furostanoside (Zhang et al., 2016). Presently, thermostable $\beta$-galactosidases have attracted considerable attention because of their significant advantages in processing, such as higher substrate solubility and reaction rate, as well as lower probability of microbial contamination.

$\beta$-Galactosidases are widely distributed in animals, higher plants, and microorganisms (Das et al., 2015). Based on sequence homology and evolutionary relationships, they can be classified into 4 distinct glycoside hydrolase families (GH): GH1, GH2, GH35, and GH42 (Yin et al., 2017). Among these, $\beta$-galactosidases of GH42 often derive from organisms that survive in extreme circumstances, such as psychrophilic, thermophilic, and halophilic conditions. Several GH42 $\beta$-galactosidases have been crystallized and studied, such as $\beta$-galactosidases from Thermus thermophilus, Rahnella spp., and Geobacillus stearothermophilus (Hidaka et al., 2002; Solomon et al., 2013; Fan et al., 2015). Generally, these enzymes consist of 600 to 700 AA residues and have 3 domains: domain A possesses a $(\beta / \alpha)_{8}$ barrel (TIM barrel), which contains catalytic residues and binding residues; domain $\mathrm{B}$ is involved in subunit polymerization; and the function of domain $\mathrm{C}$ remains unclear (Godoy et al., 2016). 
Whey is an inexpensive and abundant by-product of cheese production, the main components of which are lactose, proteins, and minerals salts. Unfortunately, it has traditionally been treated as waste and causes an important pollution issue because of its high chemical and biochemical oxygen demand, determined by lactose and whey proteins (Nath et al., 2015a,b). Given that the hydrolyzed products of lactose, glucose and galactose, are important starting materials for production of bulk and value-added chemicals (Zheng et al., 2019; Zhou et al., 2019), recycling the lactose in whey can achieve both whey valorization and environment protection. However, the numbers of microorganisms that can directly use lactose are much fewer than those able to metabolize glucose and galactose. Thus, prior hydrolysis of lactose by $\beta$-galactosidase is required for microbial bioconversion of whey (Xavier et al., 2018). Considering the high price of commercial $\beta$-galactosidases (approximately US $\$ 0.2$ per unit, Sigma-Aldrich, St. Louis, $\mathrm{MO})$, the cost of $\beta$-galactosidase will be a big part of the bioconversion process.

Bacillus coagulans is considered a GRAS (generally recognized as safe) strain. In this study, a novel $\beta$-galactosidase from $B$. coagulans NL01 (BcBga) was reported. Phylogenetic analysis and biochemical characterization were performed. The purified BcBga was used to hydrolyze high concentrations of lactose in whey and compared with the commercially purchased, unpurified BcBga.

\section{MATERIALS AND METHODS}

\section{Chemicals}

$o$-Nitrophenyl- $\beta$-D-galactopyranoside $p$-nitrophenyl- $\beta$-D-galactopyranoside $p$-nitrophenyl- $\beta$-D-xylopyranoside $p$-nitrophenyl- $\beta$-D-glucopyranoside $p$-nitrophenyl- $\alpha$-L-arabinofuranoside ( $p$ NP-Ara), lactose, and lactulose were purchased from Sigma-Aldrich. Cheese whey powder, including $70.00 \%$ (wt/wt) lactose, was purchased from Lactalis Company (Laval, France). Other chemicals were of analytical grade and commercially available.

\section{Cloning, Expression, and Purification}

The genes of $B c B g a$ and $B c B g a^{\mathrm{M}}$ (encoding a BcBga mutation lacking domain $C$ ) were amplified using the genome of $B$. coagulans NL01 as template. The primers of BcBga.f (5'-GAATTCGATGTTAAAAAAACAAGAAAAATTTTATTATG-3'; EcoRI site underlined) and BcBga.r (5'-GTCGACCTATTTTTCAAT-
TACCTGCAAAATTTTCA-3'; SalI site underlined) were used to amplify the full length of the $B c B g a$ gene. The primers of $B c B g a . f$ and $B c B g a^{\mathrm{M}}$.r (5'-GTCGACCTACGCTTCCTTTAAAATTTCTTTTAAA-3'; SalI site underlined) were used to amplify the mutant $B c B g a^{\mathrm{M}}$. The products were digested by corresponding restriction endonuclease and cloned into a pETDuet-1 expression vector that had been digested with the same enzymes to obtain recombinant plasmids, pETDuet- $B c B g a$ and pETDuet- $B c B g a^{\mathrm{M}}$. The recombinant plasmids were then transformed into $E$. coli BL21 (DE3) cells to obtain recombinant strains harboring pETDuet- $B c B g a$ or pETDuet- $B c B g a^{\mathrm{M}}$. For protein expression, transformants harboring the recombinant plasmids were inoculated into $5 \mathrm{~mL}$ of Luria-Bertani (LB) medium containing $100 \mu \mathrm{g} / \mathrm{mL}$ of ampicillin and incubated for 10 to $12 \mathrm{~h}$ at $37^{\circ} \mathrm{C}, 200 \mathrm{rpm}$. Then 5 $\mathrm{mL}$ of cell suspension was inoculated into $500 \mathrm{~mL}$ of LB medium containing $100 \mu \mathrm{g} / \mathrm{mL}$ of ampicillin. When cells were grown to an optical density at $600 \mathrm{~nm}$ of 0.6 to $0.8,1 \mathrm{~m} M$ isopropyl- $\beta$-D-thiogalactopyranoside (IPTG) was added for protein induction for a further 6 h. For protein purification, cells were harvested, washed twice with phosphate buffer ( $\mathrm{pH} 7.0$ ), and disrupted by sonication. We purified BcBga using Ni-NTA affinity chromatography from supernatant. Protein concentration was determined via the Bradford method, using BSA as the standard, and purity of BcBga was determined using SDS-PAGE.

\section{Sequence Alignment and Phylogenetic Analysis}

Database searching was performed using Blast at NCBI (www.ncbi.nlm.nih.gov) and CAZy (www.cazy .org). The multiple sequence alignment tools Clustal X 2.0 and ESPript 3.0 were used for multiple protein sequence alignment. Phylogenetic relationships were built using the neighbor-joining method with MEGA 7.0 , and the results were evaluated with 1,000 bootstrap replicates.

\section{Biochemical Assay of BcBga}

Typically, enzyme activity was measured using oNPG as substrate. We added $0.1 \mathrm{~mL}$ of diluted enzyme to 0.9 $\mathrm{mL}$ of $50 \mathrm{~m} M$ phosphate buffer $(\mathrm{pH}$ 6.0) containing 2 $\mathrm{m} M o \mathrm{NPG}$ and incubated at $55^{\circ} \mathrm{C}$ for $10 \mathrm{~min}$. The reaction was terminated by adding $2 \mathrm{~mL}$ of $0.5 \mathrm{M} \mathrm{Na}_{2} \mathrm{CO}_{3}$, and the amount of $o \mathrm{NP}$ released was measured at 420 $\mathrm{nm}$. One unit of enzyme activity was defined as the amount of enzyme releasing $1 \mu \mathrm{mol}$ of $o \mathrm{NP}$ per minute.

To determine BcBga activity for lactose, $0.1 \mathrm{~mL}$ of diluted enzyme was added to $0.9 \mathrm{~mL}$ of $50 \mathrm{~m} M$ phos- 
phate buffer ( $\mathrm{pH} 6.0)$ containing $20 \mathrm{~m} M$ lactose and incubated at $55^{\circ} \mathrm{C}$ for $10 \mathrm{~min}$. The reaction was terminated by heating at $100^{\circ} \mathrm{C}$ for $10 \mathrm{~min}$. One unit of enzyme activity was defined as the amount of enzyme required to liberate $1 \mu \mathrm{mol}$ of glucose per minute.

Optimal $\mathrm{pH}$ was determined by measuring enzyme activity at various $\mathrm{pH}$ values ranging from 4.0 to 8.0 at $37^{\circ} \mathrm{C}$. The temperature dependence of $\mathrm{BcBga}$ was assessed by measuring enzyme activity in the range of 40 to $70^{\circ} \mathrm{C}$ at $\mathrm{pH}$ 6.0. Relative enzyme activity was defined as the proportion of activity compared with that obtained at optimal $\mathrm{pH}$ or temperature.

To study $\mathrm{pH}$ stability, enzymes were incubated at various $\mathrm{pH}$ values and $0^{\circ} \mathrm{C}$ for $1 \mathrm{~h}$, and the remaining enzyme activity was measured according to standard method. For the thermal stability studies, the enzyme was incubated at various temperatures for $1 \mathrm{~h}$, and the residual enzyme activity was then measured according to standard method. The activity of the enzyme without preincubation was defined as $100 \%$.

To investigate the effect of metal ions on $\mathrm{BcBga}$ activity, purified BcBga was dialyzed against $50 \mathrm{mM}$ Tris-HCl buffer (pH 7.0) containing $10 \mathrm{mM}$ EDTA at $25^{\circ} \mathrm{C}$ for $3 \mathrm{~h}$. Then the buffer was changed to $50 \mathrm{mM}$ Tris-HCl ( $\mathrm{pH}$ 7.0) for another dialysis of $36 \mathrm{~h}$. Metallic ions $\mathrm{Na}^{+}, \mathrm{K}^{+}, \mathrm{Mg}^{2+}, \mathrm{Mn}^{2+}, \mathrm{Ni}^{2+}, \mathrm{Ca}^{2+}, \mathrm{Zn}^{2+}, \mathrm{Fe}^{3+}$, and $\mathrm{Cu}^{2+}$ ) were added into reaction mixtures containing EDTA-treated BcBga at a final concentration of $2 \mathrm{~m} M$, respectively. The activity obtained in the absence of metal ions was defined as $100 \%$.

The substrate specificity of BcBga was tested by using $o$ NPG, $p$ NPG, $p$ NP-Xyl, $p$ NP-Glu, and $p$ NP-Ara. The kinetic parameters [Michaelis constant $\left(\mathbf{K}_{\mathrm{m}}\right)$ and maximum rate of enzymatic reaction $\left.\left(\mathbf{V}_{\max }\right)\right]$ were determined according to nonlinear regression using various concentrations of $o \mathrm{NPG}$ and $p \mathrm{NPG}$. For inhibition studies, BcBga activity for lactose was measured as mentioned above, with various concentrations of galactose $(0$ to $100 \mathrm{mM}$ ) or glucose ( 0 to $500 \mathrm{~m} M)$ added in reaction system. The inhibition constant $\left(\mathbf{K}_{\mathbf{i}}\right)$ value of galactose or glucose was defined as the amount needed to inhibit $50 \%$ of the BcBga activity.

\section{Hydrolysis of Lactose in Whey}

Hydrolysis of lactose in whey was performed in 2 $\mathrm{mL}$ of $15 \%$ (wt/vol) whey solution containing $0.5 \mathrm{mg}$ of purified enzyme. The flasks were incubated at $55^{\circ} \mathrm{C}$ and $150 \mathrm{rpm}$. The concentrations of lactose, glucose, and galactose were determined via HPLC 1260 (Agilent Technologies, Santa Clara, CA) with a differential refraction detector using an Aminex HPX-87H column (Bio-Rad, Hercules, CA). The mobile phase was $5 \mathrm{mM}$ $\mathrm{H}_{2} \mathrm{SO}_{4}$ at a flow rate of $0.6 \mathrm{~mL} / \mathrm{min}$. The temperature of the column was maintained at $55^{\circ} \mathrm{C}$, and the detector temperature was maintained at $35^{\circ} \mathrm{C}$. All experiments were performed in triplicate, and error bars indicate standard deviation.

\section{RESULTS}

\section{Sequence and Phylogenetic Analysis of BcBga}

Based on the draft genome sequences of B. coagulans NL01 (Zheng et al., 2015), a gene, designated as $B c B g a$, encoding $\beta$-galactosidase, was detected. Analysis revealed that the complete $\beta$-galactosidase sequence contained an open reading frame of $1,998 \mathrm{bp}$, which encoded 665 AA with a calculated molecular mass of $76.04 \mathrm{kDa}$. Multialignment of BcBga with other GH42 $\beta$-galactosidase indicated that the enzyme can be divided into 3 domains. Domain A comprises 389 residues (M1-L382), domain $B$ is an $\alpha / \beta$ fold domain (E383A594), and domain C contains AA residues from D595 to K665. Generally, 2 glutamic acid residues are the catalytic nucleophile and proton donors in $\beta$-galactosidase. Sequence alignment revealed that E149 and E303 in domain $\mathrm{A}$ are the pivotal catalytic residues of $\mathrm{BcBga}$ (Figure 1). In domain A, R110, W311, E351, and H354 are the lactose-binding residues (Figure 1). Up to now, the function of domain $\mathrm{C}$ of GH42 $\beta$-galactosidase has been unclear. In this study, the domain $\mathrm{C}$ truncation mutant of BcBga was constructed and expressed in $E$. coli BL21 (DE3). The results showed that the mutant $\mathrm{BcBga}^{\mathrm{M}}$ was expressed as the inclusion bodies in cells (Supplemental Figure S1; https://doi.org/10.3168/jds .2019-16654), which indicates that domain $\mathrm{C}$ is an indispensable part of the enzyme.

The AA sequence analysis indicated that BcBga shared $46 \%$ sequence identity with $\beta$-galactosidase from Bacillus circulans ssp. alkalophilus (PDB: 3TTS_A), $36 \%$ of sequence identities with $\beta$-galactosidase from Bifidobacterium animalis ssp. lactis Bl-04 (PDB: ACS45863.1), and $32 \%$ of sequence identities with $\beta$-galactosidase from Thermus thermophilus A4 (PDB: O69315.1). To gain deeper insight into the relationship among the $\beta$-galactosidases, the phylogenetic tree generated from 20 candidate sequences was constructed using the neighbor-joining method. The result revealed the presence of 4 clades, each consisting of a monophyletic group. Clade I was the GH42 galactosidases, mainly derived from extremophilic microorganisms. Clade II was the GH2 galactosidases from the genera Escherichia, Arthrobacter, Bifidobacterium, and Lactobacillus. Clade III was the GH35 galactosidases, derived from fungi, and clade IV was the GH1 galactosidases. Clades I and II had a relatively close relationship and were distant from the other 2 clades (Figure 2). We 


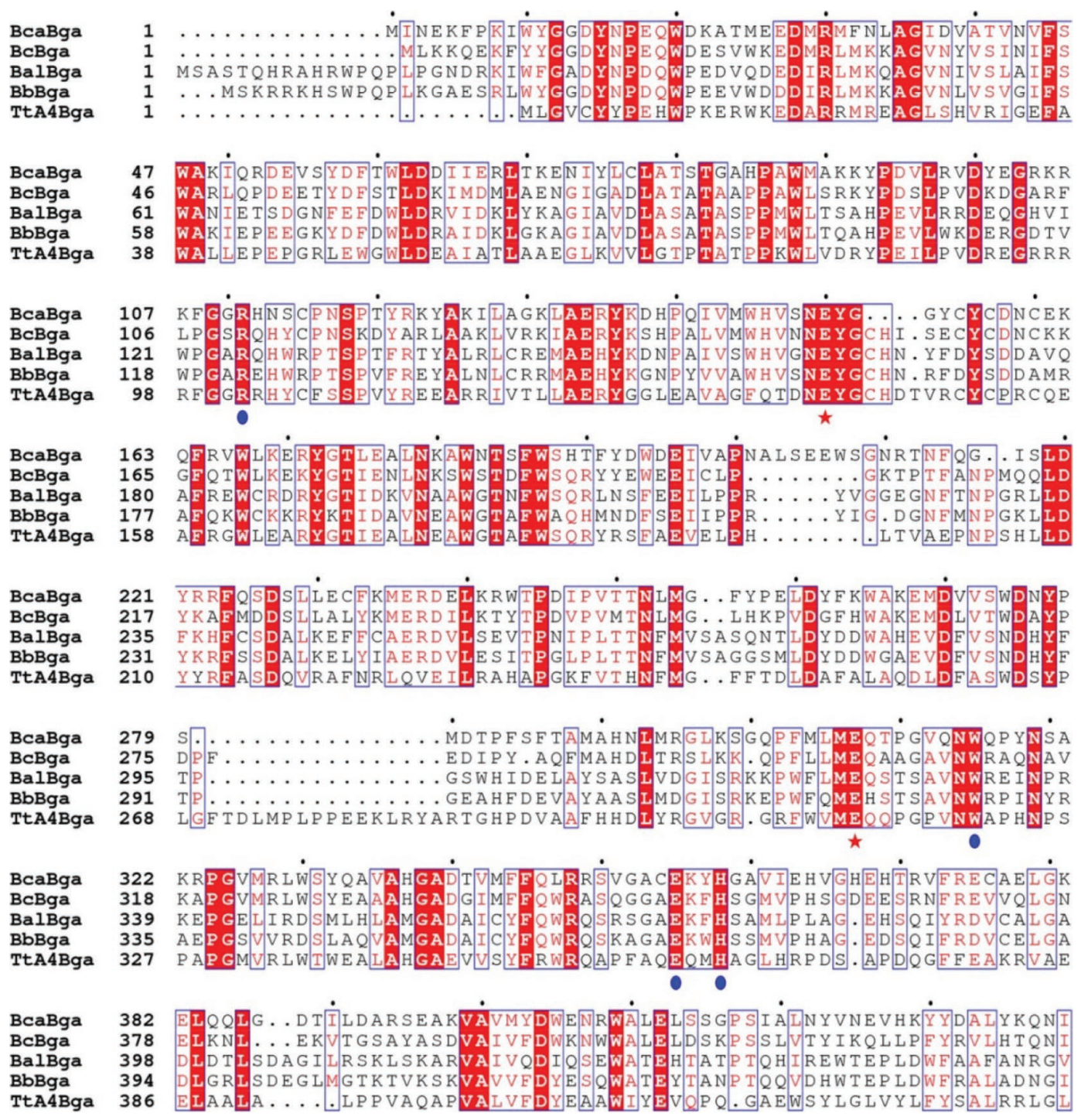

Figure 1. Multialignment of domain A of Bacillus coagulans NL01 $\beta$-galactosidase (BcBga) with other glycoside hydrolase family 42 (GH42) $\beta$-galactosidases. The catalytic residues and binding residues are indicted as red stars and blue circles, respectively, at the bottom of each alignment. BcaBga $=$ Bacillus circulans ssp. alkalophilus $\beta$-galactosidase; BalBga = Bifidobacterium animalis ssp. lactis Bl-04 $\beta$-galactosidase; BbBga $=$ Bifidobacterium bifidum S17 $\beta$-galactosidase; TtA4Bga = Thermus thermophilus A4 $\beta$-galactosidase .

found that BcBga belonged to clade I (GH42), closest to the $\beta$-galactosidase from $G$. stearothermophilus.

\section{Biochemical Properties of BcBga}

The biochemical properties of BcBga were investigated using the purified enzyme. At $\mathrm{pH}$ 6.0, BcBga displayed its highest activity, and more than $70 \%$ of its maximum activity occurred at $\mathrm{pH}$ ranging from 5.0 to 7.0. Activity fell sharply at $\mathrm{pH} 4.0$ and 8.0 (Figure 3a). $\mathrm{BcBga}$ was very stable at $\mathrm{pH} 6.5$ to 8.0 and retained more than $60 \%$ of its initial activity after incubation at $\mathrm{pH} 5.5$ for $1 \mathrm{~h}$ (Figure 3b). Optimal BcBga activity occurred at 55 to $60^{\circ} \mathrm{C}$, and $\mathrm{BcBga}$ exhibited more than $60 \%$ of the maximum activity at $65^{\circ} \mathrm{C}$ (Figure 3c). After incubation at 50 to $55^{\circ} \mathrm{C}$, even for as long as $5 \mathrm{~h}$, BcBga retained more than $65 \%$ of its initial activity, and the half-life of the enzyme was approximately $3.5 \mathrm{~h}$ at $60^{\circ} \mathrm{C}$ (Figure $3 \mathrm{~d}$ ).

After treatment with EDTA, no significant activity changes were observed in the enzyme assay. The EDTA-treated enzyme was then incubated with different metallic ions $\left(\mathrm{Na}^{+}, \mathrm{K}^{+}, \mathrm{Mg}^{2+}, \mathrm{Mn}^{2+}, \mathrm{Ni}^{2+}, \mathrm{Ca}^{2+}, \mathrm{Zn}^{2+}\right.$, $\mathrm{Fe}^{3+}$, and $\mathrm{Cu}^{2+}$ ); their effects are shown in Figure 4 . The activity of BcBga was greatly stimulated by $\mathrm{Mn}^{2+}$ and slightly enhanced by $\mathrm{Fe}^{3+}$, resulting in increases of 96.28 and $21.25 \%$, respectively. Dramatic loss of enzyme activity (82.93 and $86.65 \%$, respectively) was observed 
in the presence of $\mathrm{Cu}^{2+}$ and $\mathrm{Zn}^{2+}$. No pronounced effect was observed in the presence of $\mathrm{Ca}^{2+}, \mathrm{Mg}^{2+}, \mathrm{Na}^{+}$, or $\mathrm{K}^{+}$.

\section{Substrate Specificity and Kinetic Parameters}

The substrate specificity of BcBga was tested. The highest activity was toward $p \mathrm{NPG}$, followed by $o \mathrm{NPG}$, which exhibited $11.4 \%$ of the activity shown with $p$ NPG. Almost no activity was detected over $p$ NP-Glu, $p \mathrm{NP}-\mathrm{Xyl}$, or $p \mathrm{NP}-\mathrm{Ara}$, suggesting that BcBga has strict substrate specificity for galactosyl compounds. The dependence of the enzymatic reaction on the substrate concentration followed Michaelis-Menten kinetics, with $\mathrm{K}_{\mathrm{m}}$ and $\mathrm{V}_{\max }$ values of $1.06 \mathrm{mM}$ and $19,383.60 \mathrm{U} / \mathrm{mg}$ for $p \mathrm{NPG}$, and $2.73 \mathrm{~m} M$ and $5,978.00 \mathrm{U} / \mathrm{mg}$ for $o \mathrm{NPG}$, respectively.

\section{Hydrolysis of Lactose in Whey}

We studied the lactose hydrolysis ability of BcBga because this is its most important property for ap- plication in the dairy industry. First, enzyme activity toward lactose was determined. The specific activity of purified BcBga was 27.18 U/mg (Supplemental Table S1; https://doi.org/10.3168/jds.2019-16654). Effects of galactose and glucose on BcBga activity were also investigated with lactose as substrate. Figure 5 shows that galactose gave a much stronger inhibition than did glucose. When galactose concentration was increased, the enzyme activity of BcBga was gradually inhibited, with a $\mathrm{K}_{\mathrm{i}}$ of approximately $20 \mathrm{~m} M$ galactose. In contrast, the $\mathrm{K}_{\mathrm{i}}$ of glucose was up to $400 \mathrm{mM}$.

We further investigated the hydrolysis of lactose in whey to assess whether BcBga is appropriate for whey pretreatment. The initial concentration of cheese whey powder was $145 \mathrm{~g} / \mathrm{L}$ (corresponding to $104.02 \mathrm{~g} / \mathrm{L}$ of lactose). Even at a low enzyme concentration (2.38 $\mathrm{mg} / \mathrm{g}$ of lactose), BcBga was adequate to hydrolyze all the lactose in whey. As shown in Figure 6, 62.45\% lactose was hydrolyzed in the first $60 \mathrm{~min}$. Over time, the rate of lactose hydrolysis slowed. All lactose was completely hydrolyzed in $3 \mathrm{~h}$. The complete hydrolysis of lactose in whey indicated the suitability of BcBga for whey treatment.

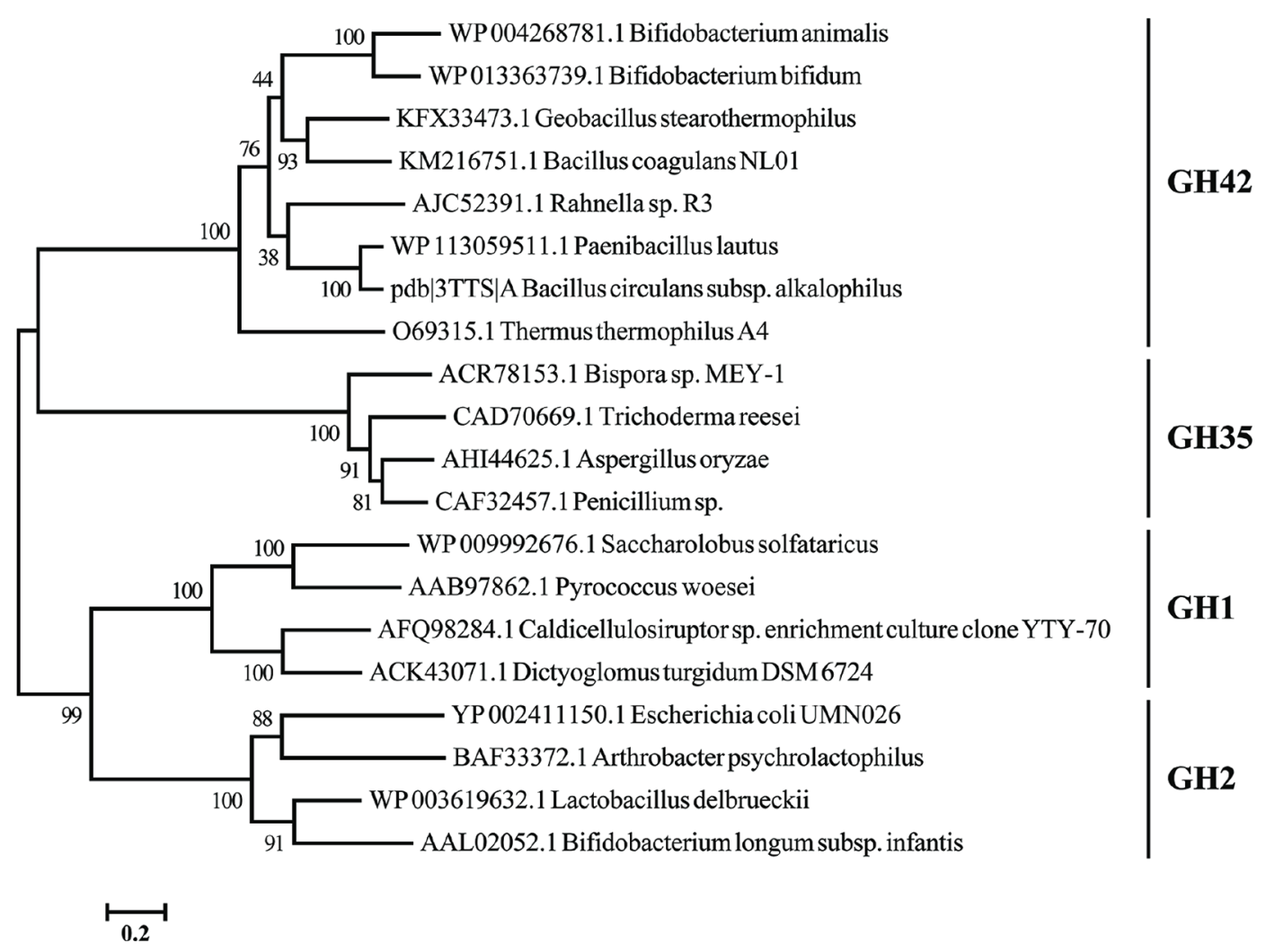

Figure 2. The neighbor-joining tree based on AA sequences of 20 different $\beta$-galactosidases. Numbers at nodes indicate the percentage of neighbor-joining bootstrap analyses with 1,000 replicates. The scale bar indicates the level of AA sequence divergence. GH = glycoside hydrolase family. 


\section{DISCUSSION}

On the basis of sequence homology, $\beta$-galactosidases are mainly grouped into GH1, GH2, GH35, and GH42 glycoside hydrolyse families. These families have distinctly different sequences and exhibit different substrate specificities. In general, GH1 and GH2 $\beta$-galactosidases demonstrate prominent lactose hydrolysis activity and have been the most widely used in food processing, water assessment, and molecular experimentation (Rodrigues and Cunha, 2017). $\beta$-Galactosidases belonging to GH35 and GH42 usually show either a very low level or a complete absence of activity toward lactose (Solomon et al., 2013). For example, Li reported GH 42 $\beta$-galactosidases from Thermotoga maritima could not cleave lactose in vitro ( $\mathrm{Li}$ et al., 2009). In contrast, we reported a GH $42 \beta$-galactosidase, from GARS strain $B$. coagulans, NL01, with outstanding lactose hydrolysis ability.

GH $42 \beta$-galactosidases often derive from microorganisms under environmental extremes and exhibit different optimal temperatures. $\beta$-Galactosidase from Arthrobacter showed the highest hydrolysis activity at $10^{\circ} \mathrm{C}$ (Pawlak-Szukalska et al., 2014), whereas the enzyme from Thermotoga naphthophila had an optimal temperature at $90^{\circ} \mathrm{C}$ (Kong et al., 2014). In our study, BcBga exhibited the highest activity at a relatively mild temperature, 55 to $60^{\circ} \mathrm{C}$, which was similar to $\mathrm{GH} 42$ $\beta$-galactosidases from B. circulans sp. alkalophilus, and Marinomonas sp. BSi20414, whose optimal temperatures are $55^{\circ} \mathrm{C}$ and $60^{\circ} \mathrm{C}$, respectively (Maksimainen et al., 2012; Ding et al., 2017). These enzymes also share a similar optimal $\mathrm{pH}$ with BcBga, near 6.0. For BcBga, the $\mathrm{pH}$ curve showed a peak with $80 \%$ of maximal $\beta$-galactosidase activity in the $\mathrm{pH}$ range of 5.5 to 6.5 , suitable for lactose hydrolysis of whey (pH 5.9 to 6.6).

Metal cations had various effects on BcBga activity. No significant enzyme activity change was observed with the addition of $\mathrm{Mg}^{2+}, \mathrm{Ca}^{+}, \mathrm{Na}^{+}$, or $\mathrm{K}^{+}$. Studies have shown that $\mathrm{Mg}^{2+}$ is beneficial to most $\beta$-galactosidase activity, such as enzymes from Kluyveromyces lactis, Lactobacillus plantarum, Thermotoga maritima, Pediococcus pentosaceus, and Pediococcus acidilactici (Iqbal et al., 2010; Katrolia et al., 2011; Lee et al., 2017; Chanalia et al., 2018; Wojciechowska et al., 2018). However, the $\beta$-galactosidase from Thermotoga
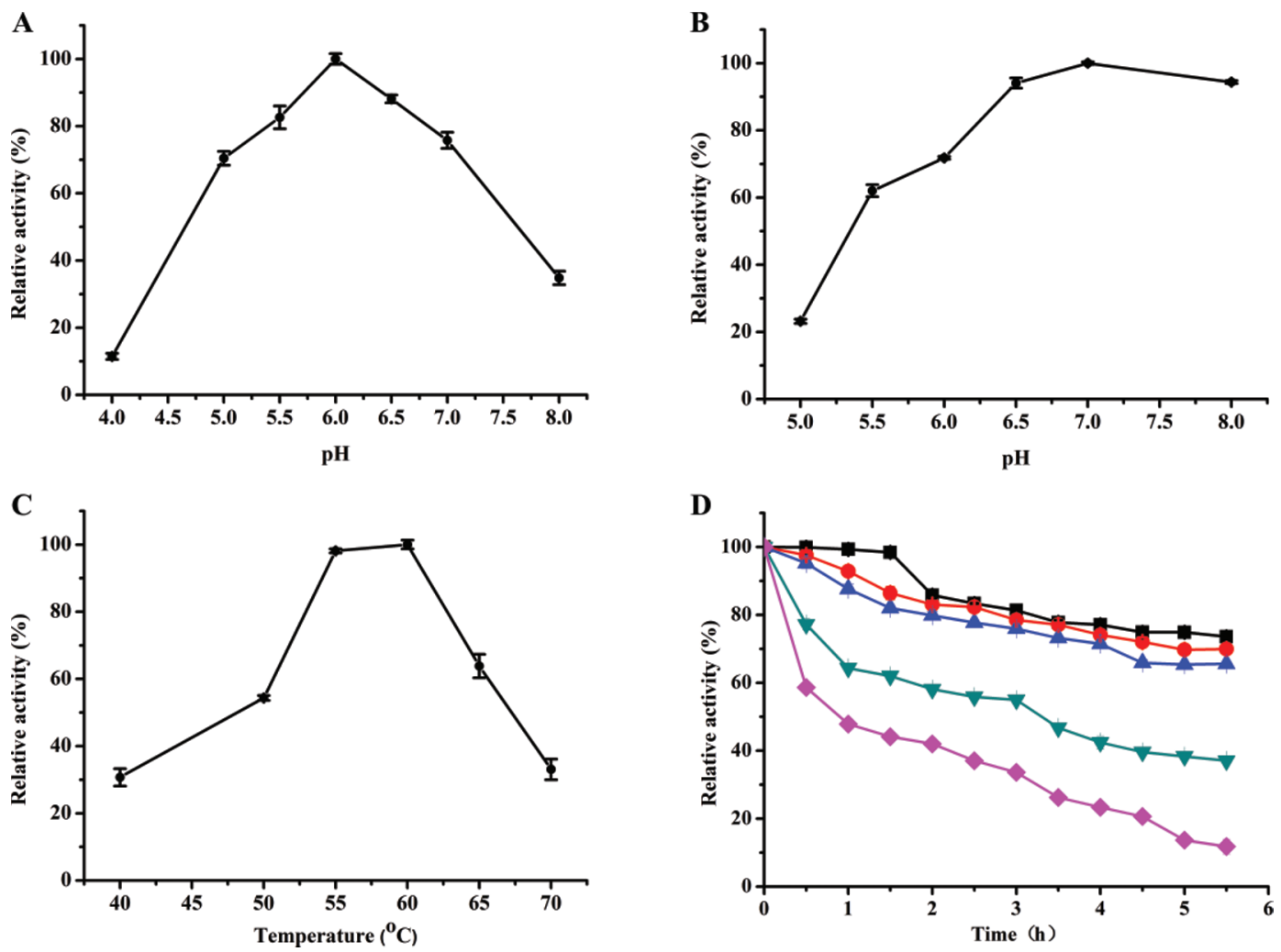

Figure 3. Effects of $\mathrm{pH}$ and temperature on the activity and stability of Bacillus coagulans NL01 $\beta$-galactosidase (BcBga). (a) Effect of pH on BcBga activity. (b) pH stability of BcBga. (c) Effect of temperature on BcBga activity. (d) Thermostability of BcBga over time. Symbol key: Black squares $(\boldsymbol{\square})=45^{\circ} \mathrm{C}$; red circles $(\bullet)=50^{\circ} \mathrm{C}$; blue upward-pointing triangles $(\boldsymbol{\Delta})=55^{\circ} \mathrm{C}$; green downward-pointing triangles $(\mathbf{\nabla})=60^{\circ} \mathrm{C}$; pink diamonds $(\bullet)=65^{\circ} \mathrm{C}$. The highest activity was defined as $100 \%$. Error bars indicate standard deviation. 


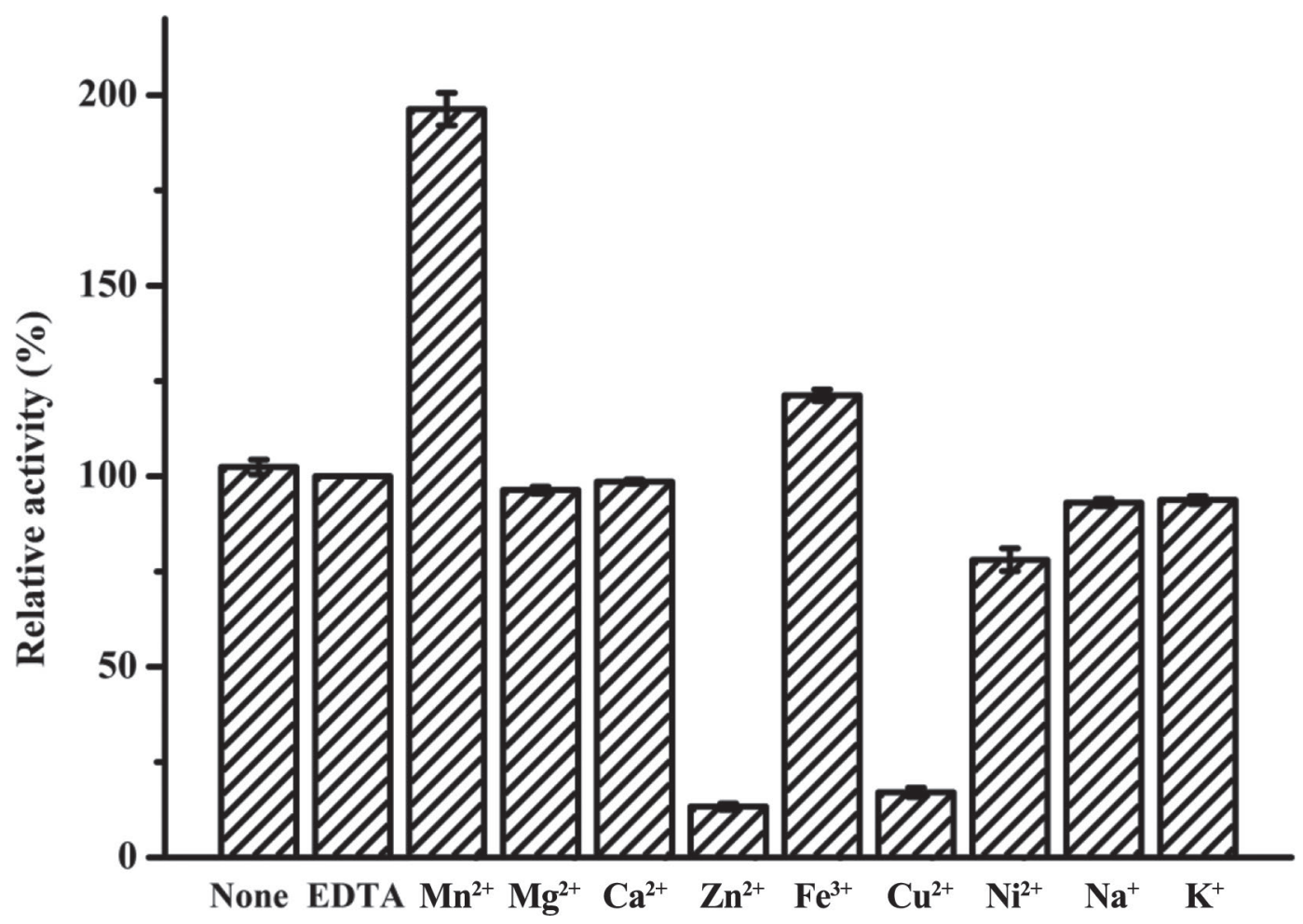

Figure 4. Effects of metal ions on Bacillus coagulans NL01 $\beta$-galactosidase (BcBga) activity. None = purified BcBga without EDTA treatment; EDTA = purified BcBga treated by EDTA. The EDTA-treated enzyme was used to determine the effects of metal ions. Error bars indicate standard deviation.

naphthophila RUK-10 was inhibited by $\mathrm{Mg}^{2+}$ (Kong et al., 2014) Figure 4 shows that our findings contradict these reports. It should be noticed that BcBga was not inhibited by $\mathrm{Ca}^{2+}$, which is beneficial for its use in the dairy industry.

In the crystal structure, the GH42 $\beta$-galactosidase polypeptide chain forms 3 domains. Domain $\mathrm{A}$ is the catalytic domain, containing an $(\alpha / \beta)_{8}$ barrel. Domain $\mathrm{B}$ has a complicated $(\alpha / \beta)$ structure, often with a central 7-stranded mixed $\beta$-sheet and $5 \alpha$-helices. The function of domain B is structural, as it forms a major interface with other monomers. Domain $\mathrm{C}$ is the smallest, and its function has thus far been unclear (Godoy et al., 2016). In this study, we constructed a domain C truncation mutant of GH42 $\beta$-galactosidase $\left(\mathrm{BcBga}^{\mathrm{M}}\right)$ for the first time and found that the mutant generated insoluble protein products, suggesting that domain $\mathrm{C}$ might be indispensable to the correct folding of BcBga.
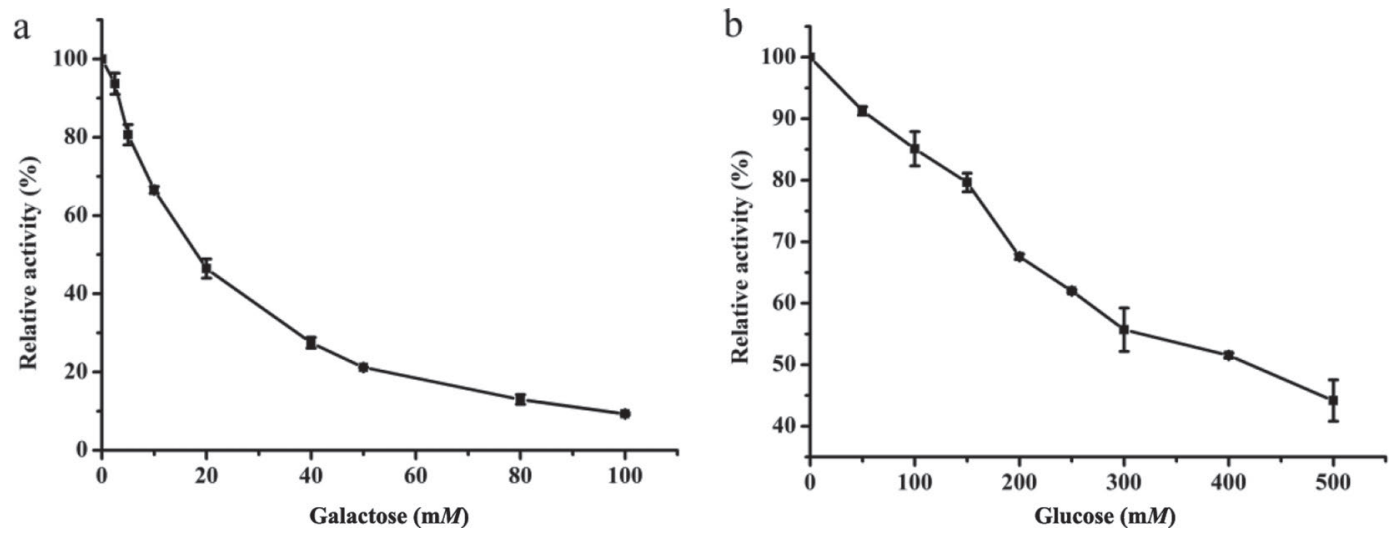

Figure 5. Effects of (a) galactose and (b) glucose on Bacillus coagulans NL01 $\beta$-galactosidase (BcBga) activity with lactose as substrate. Error bars indicate standard deviation. 


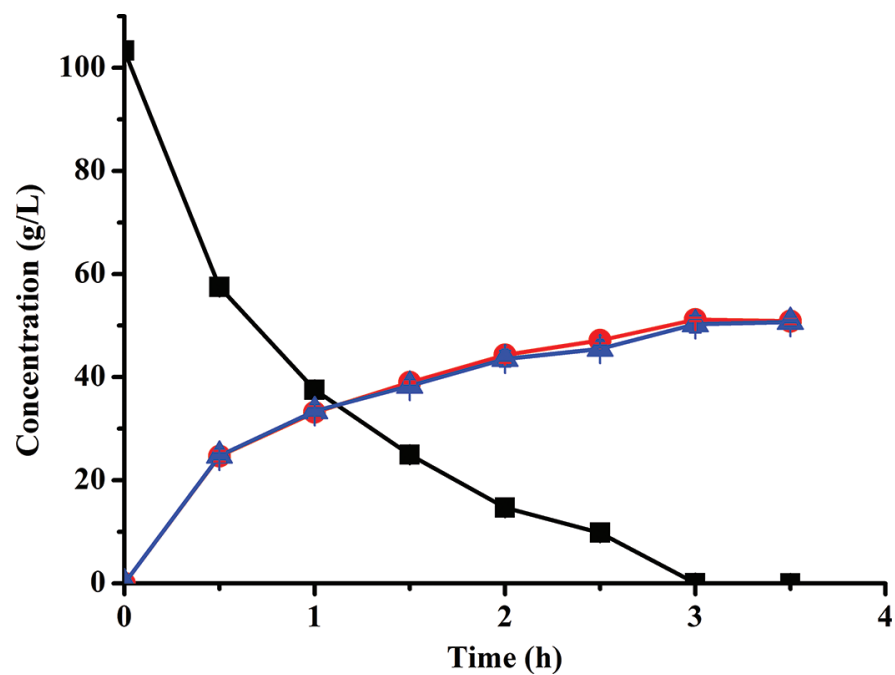

Figure 6. Time course of hydrolysis of lactose in whey by the purified Bacillus coagulans NL01 $\beta$-galactosidase (BcBga). Symbol key: (black $\mathbf{\square}$ ), lactose; (red $\bullet$ ), galactose; (blue $\boldsymbol{\Lambda}$ ), glucose. Error bars indicate standard deviation.

The ability of $\beta$-galactosidase to hydrolyze lactose is crucial to its application in the dairy industry. Previous studies have revealed that most GH42 $\beta$-galactosidases prefer to hydrolyze chromogenic substrates and show weak lactose hydrolysis activity. Few GH42 $\beta$-galactosidases have thus far been applied to hydrolyze the lactose in milk or whey. Unexpectedly, the $\beta$-galactosidase of $B$. coagulans NL01 exhibited admirable lactose hydrolysis ability. Generally, GH2 $\beta$-galactosidase is the best-known enzyme possessing good lactose hydrolysis activity. Zhou et al. (2019) employed the commercial $\beta$-galactosidase produced by K. lactis (GH2, Sigma-Aldrich, G3665) for hydrolysis of lactose in whey. About $140 \mathrm{~g} / \mathrm{L}$ of lactose in whey was hydrolyzed by $\beta$-galactosidase, with $3.8 \mathrm{mg} / \mathrm{g}$ of lactose. However, the hydrolysis rate of this commercial $\beta$-galactosidase is much slower than BcBga, as it took $72 \mathrm{~h}$ to achieve a hydrolysis yield of $93.9 \%$ (Zhou et al., 2019).

\section{CONCLUSIONS}

In this study, a novel $\beta$-galactosidase from $B$. coagulans NL01 was cloned and analyzed. Based on sequence homology, BcBga was assigned to GH42, but it exhibited excellent hydrolysis activity, with activities toward $o \mathrm{NPG}, p \mathrm{NPG}$, and lactose reaching $5,978.00 \mathrm{U} / \mathrm{mg}$, $19,383.60 \mathrm{U} / \mathrm{mg}$, and $27.18 \mathrm{U} / \mathrm{mg}$, respectively. Compared with commercial $\beta$-galactosidase from $K$. lactis, $\mathrm{BcBga}$ is a superior candidate for wide application in whey treatment, which can offset the high production cost of whey valorization.

\section{ACKNOWLEDGMENTS}

This study was supported by the National Natural Science Foundation of China (51561145015), Beijing.

\section{REFERENCES}

Chanalia, P., D. Gandhi, and P. Attri. 2018. Purification and characterization of $\beta$-galactosidase from probiotic Pediococcus acidilactici and its use in milk lactose hydrolysis and galactooligosaccharide synthesis. Bioorg. Chem. 77:176-189.

Das, B., A. P. Roy, S. Bhattacharjee, S. Chakraborty, and C. Bhattacharjee. 2015. Lactose hydrolysis by $\beta$-galactosidase enzyme: Optimization using response surface methodology. Ecotoxicol. Environ. Saf. 121:244-252.

Ding, H., Q. Zeng, L. Zhou, Y. Yu, and B. Chen. 2017. Biochemical and structural insights into a novel thermostable $\beta$-1,3-galactosidase from Marinomonas sp. BSi20414. Mar. Drugs 15:13.

Fan, Y., X. Hua, Y. Zhang, Y. Feng, Q. Shen, J. Dong, W. Zhao, W. Zhang, Z. Jin, and R. Yang. 2015. Cloning, expression and structural stability of a cold-adapted $\beta$-galactosidase from Rahnella sp. R3. Protein Expr. Purif. 115:158-164.

Godoy, A. S., C. M. Camilo, M. A. Kadowaki, H. D. Muniz, M. Espirito Santo, M. T. Murakami, A. S. Nascimento, and I. Polikarpov. 2016. Crystal structure of 31-6-galactosidase from Bifidobacterium bifidum S17: Trimeric architecture, molecular determinants of the enzymatic activity and its inhibition by $\alpha$-galactose. FEBS J. 283:4097-4112

Hidaka, M., S. Fushinobu, N. Ohtsu, H. Motoshima, H. Matsuzawa, H. Shoun, and T. Wakagi. 2002. Trimeric crystal structure of the glycoside hydrolase family $42 \beta$-galactosidase from Thermus thermophilus A4 and the structure of its complex with galactose. J. Mol. Biol. 322:79-91

Iqbal, S., T. H. Nguyen, and T. T. Nguyen. 2010. $\beta$-Galactosidase from Lactobacillus plantarum WCFS1: Biochemical characterization and formation of prebiotic galacto-oligosaccharides. Carbohydr. Res. 345:1408-1416.

Katrolia, P., M. Zhang, and Q. Yan. 2011. Characterisation of a thermostable family $42 \beta$-galactosidase (BgalC) family from Thermotoga maritima showing efficient lactose hydrolysis. Food Chem. 125:614-621.

Kong, F., Y. Wang, S. Cao, R. Gao, and G. Xie. 2014. Cloning, purification and characterization of a thermostable $\beta$-galactosidase from Thermotoga naphthophila RUK-10. Process Biochem. 49:775-782.

Lee, J. Y., M. S. Kwak, and J. B. Roh. 2017. Microbial $\beta$-galactosidase of Pediococcus pentosaceus ID-7: Isolation, cloning, and molecular characterization. J. Microbiol. Biotechnol. 27:598-609.

Li, L., M. Zhang, Z. Jiang, L. Tang, and Q. Cong. 2009. Characterisation of a thermostable family $42 \beta$-galactosidase from Thermotoga maritima. Food Chem. 112:844-850.

Lu, L., S. Xu, L. Jin, D. Zhang, Y. Li, and M. Xiao. 2012. Synthesis of galactosyl sucralose by $\beta$-galactosidase from Lactobacillus bulgaricus L3. Food Chem. 134:269-275.

Maksimainen, M., S. Paavilainen, N. Hakulinen, and J. Rouvinen. 2012. Structural analysis, enzymatic characterization, and catalytic mechanisms of $\beta$-galactosidase from Bacillus circulans sp. alkalophilus. FEBS J. 279:1788-1798.

Nath, A., S. Chakrabarty, S. Sarkar, C. Bhattacharjee, E. Drioli, and R. Chowdhury. 2013. Purification and characterization of $\beta$-galactosidase synthesized from Bacillus safensis (JUCHE 1). Ind. Eng. Chem. Res. 52:11663-11672.

Nath, A., S. Chakraborty, C. Bhattacharjee, and R. Chowdhury. 2015a. Studies on the separation of proteins and lactose from casein whey by cross-flow ultrafiltration. Desalination Water Treat. 54:481-501.

Nath, A., S. Mondal, S. Chakraborty, C. Bhattacharjee, and R. Chowdhury. 2014. Production, purification, characterization, immobilization, and application of $\beta$-galactosidase: a review. Asia-Pac. J. Chem. Eng. 9:330-348. 
Nath, A., S. Mondal, T. Kanjilal, S. Chakraborty, S. Curcio, and C. Bhattacharjee. 2015b. Synthesis and functionality of proteinacious nutraceuticals from casein whey-A clean and safe route of valorization of dairy waste. Chem. Eng. Res. Des. 97:192-207.

Oh, S. Y., M. S. Park, and Y. G. Lee. 2019. Enzymatic synthesis of $\beta$-galactosyl fucose using recombinant bifidobacteria $\beta$-galactosidase and its prebiotic effect. Glycoconj. J. 36:199-209.

Pawlak-Szukalska, A., M. Wanarska, A. Popinigis, and J. Kur. 2014 A novel cold-active $\beta$-D-galactosidase with transglycosylation activity from the Antarctic Arthrobacter sp. 32cB-Gene cloning, purification and characterization. Process Biochem. 49:2122-2133.

Rodrigues, C., and M. Â. Cunha. 2017. Assessment of the microbiological quality of recreational waters: Indicators and methods. Euro-Mediterranean Journal for Environmental Integration. 2:25.

Solomon, H. V., O. Tabachnikov, H. Feinberg, L. Govada, N. E. Chayen, Y. Shoham, and G. Shoham. 2013. Crystallization and preliminary crystallographic analysis of GanB, a GH42 intracellular ß-galactosidase from Geobacillus stearothermophilus. Acta Crystallogr. Sect. F Struct. Biol. Cryst. Commun. 69:1114-1119.

Wojciechowska, A., R. Klewicki, and M. Sójka. 2018. Application of transgalactosylation activity of $\beta$-galactosidase from Kluyveromyces lactis for the synthesis of ascorbic acid galactoside. Appl. Biochem. Biotechnol. 184:386-400.

Xavier, J., K. Ramana, and R. Sharma. 2018. ß-Galactosidase: Biotechnological applications in food processing. J. Food Biochem. 42:e12564.
Yang, J., B. Pérez, S. Anankanbil, J. Li, R. Gao, and Z. Guo. 2017 Enhanced synthesis of alkyl galactopyranoside by Thermotoga naphthophila $\beta$-galactosidase catalyzed transglycosylation: Kinetic insight of a functionalized ionic liquid-mediated system. ACS Sustain. Chem.\& Eng. 5:2006-2014.

Yin, H., T. Pijning, and X. Meng. 2017. Biochemical characterization of the functional roles of residues in the active site of the $\beta$-Galactosidase from Bacillus circulans ATCC 31382. Biochemistry 56:3109-3118.

Zhang, J., L. Lu, L. Lu, Y. Zhao, L. Kang, X. Pang, J. Liu, T. Jiang, M. Xiao, and B. Ma. 2016. Galactosylation of steroidal saponins by $\beta$-galactosidase from Lactobacillus bulgaricus L3. Glycoconj. J. $33: 53-62$.

Zheng, Z., T. Jiang, X. Lin, J. Zhou, and J. Ouyang. 2015. Draft genome sequence of Bacillus coagulans NL01, a wonderful L-lactic acid producer. Genome Announc. 3:e00635-15.

Zheng, Z., J. Xie, P. Liu, X. Li, and J. Ouyang. 2019. Elegant and efficient biotransformation for dual production of D-tagatose and bioethanol from cheese whey powder. J. Agric. Food Chem. $67: 829-835$.

Zhou, X., X. Hua, L. Huang, and Y. Xu. 2019. Bio-utilization of cheese manufacturing wastes (cheese whey powder) for bioethanol and specific product (galactonic acid) production via a two-step bioprocess. Bioresour. Technol. 272:70-76. 